\title{
8
}

\section{Clarity in Teaching in Higher Education: Dimensions and Classroom Strategies}

\section{Nira Hativa}

Tel Aviv University

This essay presents research knowledge regarding the main dimensions of effective teaching in higher education, concentrating on clarity in teaching and its components-classroom behaviors and strategies that promote clear teaching. On this basis, I suggest arranging all dimensions and classroom strategies of effective teaching within a logical structure of interconnected teaching behaviors whose contribution to student learning is based on theory and research. The model organizes all dimensions and strategies of effective teaching in three hierarchical levels and is illustrated by successively breaking down clarity in teaching into intermediate dimensions and classroom behaviors and strategies. The model may belp faculty understand how classroom strategies work-bow they contribute to the higher dimensions of effective teaching, and eventually to student learning. In this way, understanding the model may promote faculty knowledge of and motivation for adopting and using effective strategies in teaching, and their perception of teaching as a scientific activity rather than a disorganized and random collection of isolated techniques with no scientific rationale and structure.

\section{Dimensions, Behaviors, AND Strategies of EfFective Teaching}

$\mathbf{R}$ ecent research has identifed the main dimensions of, and specific $R_{\text {strategies and techniques for, effective college and university teach- }}$ ing. The four main dimensions of effective classroom teaching mostly agreed upon in research are 1) clarity/understableness, 2) organization/ structure, 3) interest/enthusiasm/expressiveness, and 4) interaction/ 
rapport with students (e.g., Feldman, 1989; Marsh \& Dunkin, 1997; Murray, $1983 ; 1997)$. In addition, research and practice identified hundreds of classroom-specific teaching behaviors and strategies that contribute to effective teaching. They are listed in a variety of publications by teaching centers in universities and colleges, and in books on teaching tips/techniques (e.g., McKeachie, 1999). Knowledge of effective classroom teaching strategies bears several important practical applications. These behaviors serve as items in teacher evaluation forms and in observation tools in case study research on teaching. But their most important application is for instructional development - to guide teachers in using classroom strategies that improve their effectiveness.

Because of the large number of beneficial teaching strategies and techniques available, researchers tend to group them under categories of the occasion for use or on the basis of some general psychological principles. To illustrate, in McKeachie's book, they are grouped under headings such as "meeting a class for the first time," "organizing effective discussions," "lecturing," "peer learning, collaborative learning, cooperative learning," and "learning and cognition in the college classroom." However, although the main dimensions of effective teaching were identified primarily by using factor analysis of teacher behavior in the classroom in teacher evaluation forms, it is rare to find in the literature distinct links between classroom behaviors and the main dimensions of effective teaching, along with explanations of how these behaviors contribute to the main dimensions.

\section{Clarity in Teaching}

I hereby offer a model that connects classroom teaching strategies to the main dimensions of effective teaching. To illustrate the suggested model, I concentrate on one of these dimensions-on teaching clarity. The term clarity is frequently mentioned in the context of teaching. Every so often we hear students complain of unclear teachers or instructors who state that they have explained a difficult concept clearly. Hativa and Raviv (1996) identified teacher ratings on clarity to be consistent across time and courses, suggesting that students have a good perception of the nature of clear teaching. Clarity is essential for effective teaching. A review summarizing almost two decades of research on teacher clarity concluded that:

Although there is evidence to suggest that a number of teacher behaviors facilitate learning (e.g., enthusiasm, variability, task orientation), there also is growing evidence that clarity of explanation may be the requisite of effective teaching, at least effective expository teaching (Cruickshank \& Kennedy, 1986, p. 43). 
Moreover, studies found strong correlation between teaching clarity and student learning and their satisfaction from instruction. This was found for all school levels, and across all providers of measurementobservers, learners, and teachers through self-ratings (Evans \& Guymon, 1978; Feldman, 1997; Hines, 1982; Hines, Cruickshank, \& Kennedy, 1985; Rosenshine \& Furst, 1971). Unclear instructors confuse students, diminish their understanding of the material and their self confidence as learners, increase their anxiety, and force them to invest extra time and effort in learning from sources, particularly the textbook, other than the teacher (Hativa, 1984). In spite of its importance to student learning, clarity in teaching received only little attention as compared with other dimensions of effective teaching, and most related research has concentrated primarily on the pre-college level.

What is the meaning of clarity in teaching? Most clarity studies did not define this notion. The few studies that did offer a definition related it to student understanding of the material taught during the lesson, as opposed to mere rote learning (e.g., Feldman, 1989; Hativa, 1998; Hines et al., 1985). For student understanding I hereby adopt the following definition:

'Understanding' refers to an individual's ability to use knowledge in novel situations, for example, to solve problems, fashion products, or create stories . . Understanding is the ability to think with knowledge, according to the standards of good practice within a specific domain, such as math, history, ceramics, or dance (Boix, 1997, p. 382).

This essay focuses on classroom teaching strategies that promote clear teaching. Several dozens of these strategies have already been identified (e.g., Bush, Kennedy, \& Cruickshank, 1977; Cruickshank, Kennedy, Bush, \& Meyers, 1979; Hines, 1982), too many to be all included in teacher evaluation forms or in tools for rating classroom behavior by observers. Thus, we need to identify from this pool of strategies those that most strongly contribute to clear teaching.

\section{Which Classroom Strategies Make the Strongest Contribution to Lesson Clarity?}

Major attempts have already been made to arrange clarity-related classroom strategies in order of importance or of frequency of use. A group of researchers centered at Ohio State University (e.g., Cruickshank et al., 1979; Kennedy, Cruickshank, Bush, \& Myers, 1979) started this work by asking pre-college-level students to describe relevant strategies of their 
most clear and most unclear teachers. Analyses of these descriptions identified over 100 clarity strategies. The researchers' next step was to give a list of these strategies to students to rate each on its extent of use by teachers who had high and low on clarity rating. On the basis of students' responses, researchers sorted these strategies on their level of contribution to clarity. Hines (1982) extended these studies to the university level. She listed 53 classroom clarity strategies identified either in these earlier studies or through observation and analysis of university teaching. She then assigned undergraduate students to rate the occurrence of each listed behavior twice - with reference to their highest-clarity teachers and to their lowest-clarity ones. Hines then used discriminate analysis of student responses to arrange the strategies in decreasing order of discriminating power between high- and low-clarity instructors. The first 28 prime discriminators on her list, in decreasing order of discriminating power, are:

1) Gives explanations students understand

2) Presents content in a logical manner

3) Explains things simply

4) Teaches at an appropriate pace

5) Answers students' questions

6) Asks questions to find out if students understand

7) Repeats things that are important in handouts

8) Repeats things when students do not understand

9) Points out what is important to learn

10) Stays with the topic until students understand

11) Summarizes the material presented in class

12) Asks students if they know what to do and how

13) Distributes time adequately over topics.

14) Explains the assignments and the materials students need to use
15) Explains and then stops for questions

16) Tells students what they are expected to do/know

17) Stresses difficult points

18) Describes the assignments and how to do them

19) Teaches step-by-step

20) Allows students time to ask questions

21) Writes important things on board or

22) Shows how to remember things

23) Uses examples when explaining

24) Shows similarities and differences between things

25) Compares new material with what students know

26) Goes over difficult problems in class

27) Explains meaning of unfamiliar words

28) Explains and stops for students to think about it

In another type of study, Murray (1985) used a factor analysis procedure to identify from observers' ratings of an initial list of 93 classroom strategies, those that load the highest on lesson clarity. In the following list of the items identified, ${ }^{*}$ marks those that significantly correlate with students' ratings of the same teacher on overall performance. In parentheses are the corresponding items in Hines's study: 
a) Uses concrete examples of concepts (23)

b) Stresses important points* $(7,9,21)$

c) Gives multiple examples* (23)

d) Points out practical applications

e) Repeats difficult ideas $(8,10,17,26)$

Two additional items-on questions in the classroom-found by Murray as loading on another main dimension of effective teaching (interaction), appear in Hines's list as prime discriminators of clarity. These are:

f) Encourages questions and comments ${ }^{*}(5,15,20)$

g) Asks questions of class" (6)

Indeed, questions may belong in both categories - interaction and clarity-as they form the basis for any good teacher-student interaction and make an essential contribution to clear teaching. This contribution is based on posing questions to gauge students' understanding to then fill in the gaps, or encouraging students to ask questions when they do not understand and then answering these questions and continuing to explain until students understand. Unfortunately, there is no indication in Murray's list on the loading of these two items on clarity as a main dimension of effective teaching.

Smith (1978) used trained raters to rate the videotaped classroom teaching of 99 community college teachers' clarity. The ten strategies that were most highly related to overall teacher clarity were:

1) Uses examples with explicit referents

2) Lets students ask questions

3) Answers student questions

4) Asks questions related to material taught

5) Encourages students to ask questions
6) Shares overall structure of lecture with students

7) Teaches step-by-step

8) Prepares students for what is upcoming

9) Uses verbal markers of importance

10) Summarizes material at appropriate points in the presentation

A more recent study (Benz \& Blatt, 1994) used qualitative methods to identify components of teaching effectiveness. University students were asked to explain in writing why they rated their teachers as they did on the standard rating questionnaire. The most frequent explanations for ratings of a teacher as very clear were:

a) Explains the subject matter well 
b) Repeats explanations

c) Presents in an orderly manner

d) Uses examples

e) Personalizes examples

f) Uses frequent questioning

The substantial similarity of strategies identified as components of clarity in the different studies, conducted in different types of institutions, locations, and using different research methods provides validity to those clarity behaviors and strategies.

To summarize, the components-classroom strategies and behaviors-of clarity that are found repeatedly, in at least two of these four studies, are (in parentheses, the number of studies):

1) Using examples when explaining (4)

2) Posing questions to students (to find out if they understand) (4)

3) Enabling/encouraging students to ask questions (4)

4) Answering students' questions (3)

5) Repeating things when students do not understand (3)

6) Relating material/explanations to students' prior knowledge/experience (3)

7) Stressing important points (e.g., by writing on the board or in handouts, repeating them) (2)

8) Summarizing the material (at appropriate points in the presentation) (2)

9) Teaching step-by-step (2)

10) Presenting content in a logical/orderly manner (2)

The following are most of the rest of items found only once in those four studies:

11) Staying with the topic until students understand

12) Giving sufficient "wait time"-frequently stopping for students to think 
13) Pointing out practical applications

14) Describing the assignments and how to do them

15) Going over difficult problems in class

16) Showing similarities and differences between things

17) Going over difficult problems in class

18) Teaching at an appropriate pace

Altogether, this list suggests the main classroom strategies to adopt for promoting their clarity in teaching.

\section{A Model for Dimensions of Clarity in Teaching}

\section{Rationale}

Providing college and university faculty with a list of strategies may be very beneficial in promoting their teaching effectiveness. However, providing lists of do's and don'ts has some shortcomings. There is a growing tendency to promote the perception of teaching in higher education as scholarly work. According to this approach, teaching should be perceived as an act of intellectual invention, deserving faculty's time and attention, and its status, especially in research universities, should be raised to the same level as that of research (Shulman \& Hutchings, 1997). In this approach, the current view of teaching by faculty as "simply a matter of methods and techniques" (p. 7) should change to that of a scientific activity. Providing faculty with a list of do's and don'ts promotes their perception of teaching as a disorganized and occasional collection of isolated techniques with no scientific rationale and structure.

I suggest arranging all dimensions and classroom strategies in a logical structure of interconnected teaching behaviors whose contribution to student learning is based on theory and research. An important strategy for effective teaching is using an advance organizer-providing students with a general framework of a lesson or a topic of study before going into detail. This framework serves as a basis for embedding the content of the lesson/topic (e.g., Ausubel, 1978). For the same reason we need to provide college and university faculty with a general framework of effective instructional dimensions and strategies before giving them lists of specific effective classroom teaching behaviors. The model I suggest provides a general framework of interconnections between dimensions and classroom strategies and thus may promote faculty's perception of teaching as 
having a scientific structure, rather than being simply a matter of methods and techniques, or an aggregation of unrelated teaching techniques.

\section{Breaking Down Clarity into Categories and Subcategories}

There are probably a variety of alternatives for breaking down clarity into categories, subcategories, and classroom behaviors. The following is my suggestion for the breakdown of clarity, using content analysis based on my experience working with faculty members on instructional development, on analysis of many dozens of hours of videotaped lessons, and on my previous studies (e.g., Hativa, 1983; 1985; 1995; 2000).

First, I have broken down the notion of 'clarity' into four components:

a) Simplifying the material presented

b) Avoiding "noise" in teaching

c) Adapting instruction and explanations to the students

d) Clarifying after completing instruction

I have further broken down each of these first-level components into subcategories:

a) Simplifying the material presented

i) Teaching in two (or more) cycles

ii) Teaching in small steps

iii) Identifying the main points

iv) Building explanations in a logical sequence

These are still not concrete classroom behaviors, so that each of them can be further broken down. Let us concentrate on (i) Teaching in two (or more) cycles. This teaching strategy starts with teaching a new topic by presenting its easier-to-comprehend aspects, or a simplified version of the topic, and teaching the more complex version only after the first version is sufficiently understood. Each subsequent teaching cycle is presented at a somewhat more complex and difficult level than the previous one. The cycles are not necessarily presented sequentially; they may be presented concurrently; in parallel; or in a spiral format, integrated with one another. Teaching in two or more cycles is based on a well-known 
pedagogical method named the spiral principle (Bruner, 1960) that rests on the same idea: Teach a topic in a few cycles-start with the simplest and build up the following ones so that each is somewhat more complicated and difficult than the previous ones. There are several techniques for presenting a simplified version of the new topic in the first cycle. For example:

i) Teaching in two (or more) cycles.

1) Presenting a concrete case before discussing an abstract notion

2) Presenting a comparable case that is familiar to the students (an example, an analogy, a metaphor, a similar or a contradicting case)

3) Presenting a visual or intuitive interpretation of the formal or abstract topic to be taught

4) Presenting a rough notion of a concept or figure before going to the more complex but accurate one

5) Presenting a plan for action, and only then performing the plan

6) Presenting first the core notion before giving all the details

Similarly, the breakdown of the other categories of a) simplifying the material presented follow (Hativa, 2000):

ii) Teaching in small steps.

1) Breaking down the topic into small chunks

2) Arranging the chunks in a coherent logical sequence (see category (d))

3) Teaching each chunk until students understand, before going to the next one

iii) Identifying the main points:

1) Emphasizing/stressing main points by varying intonation, writing on the board or on transparencies, stressing points verballyby marking and signaling

2) Repeating important points

3) Summarizing the main points 
iv) Building explanations in a logical sequence.

1) Concentrating on the main line of thought

2) Going smoothly from one idea or step to the next without diverging into irrelevant material

3) Coherently tying together the different ideas in the presentation

4) Using properly transitions (transitional phrases)

5) Avoiding skipping steps in a sequence, in proofs, developments, or explanations

6) Avoiding leaving out pieces of information for students to fill in themselves, without clear guidance on how to do this

7) Avoiding making frequent errors

8) Avoiding "jumping around" in presentations

This was a short elaboration on a) Simplifying. I do not elaborate on all the subcategories of clarity in teaching because doing this in depth will be too long for the aim of this essay-to demonstrate the breakdown process of the main dimension of clarity. I only present hereby in short the breakdown of d) Clarifying after completing instruction. Gaining a full and meaningful understanding of the material taught is established only when students can apply this knowledge by demonstrating understanding performances-performing some thinking tasks that are based on that material. The tasks can be of a diverse nature such as explaining, providing illustrations and analogies, comparing and contrasting, providing evidence and justification, putting in context, generalizing, applying and transferring to new situations, and solving problems (Perkins, $1992 ; 1998)$. A full level of understanding is gained gradually during the lesson and after the lesson (e.g., through solving related problems or doing other homework assignments). To deepen students' understanding within the framework of the lesson and help them retain and apply the new material, teachers should add clarification procedures after students have supposedly gained basic comprehension of the material-upon completion of teaching a topic. The main clarification procedures that teachers use in this case are

d) Clarifying after completing instruction

i) Looking back (i.e., laying the basis for "understanding performances") 
1) Recapitulating the core idea, or the end result

2) Simulating the process or reviewing the steps

ii) Sharpening the meaning (i.e., demonstrating understanding performances)

1) Providing additional examples and illustrations (additional to those presented while teaching the material in the first time)

2) Providing additional analogies, metaphors, and visual or intuitive interpretations

3) Showing similarities, and discriminating between similar cases

4) Showing positive as well as negative examples

5) Presenting cases of use and misuse of the new concepts, and cases of nonexamples

6) Stressing main attributes

7) Presenting special cases, limit/border cases

8) Presenting applications

9) Identifying the type/category; stating which cases would apply in what conditions/ occasions

iii) Helping students apply learned material (i.e., training students in understanding performances)

1) Demonstrating solutions to problems

2) Providing algorithms for procedures and processes

3) Providing plans for action

All the behaviors and strategies identified in the four studies of clarity components are included in this structure, and moreover, the structure presents many more behaviors of this type. We can explain how these subcategories and behaviors contribute to lesson clarity, using the psychological information-processing model. For example, "avoiding noise" enables for the listener to take in the teacher input through the senses whereas simplifying the material presented, adapting instruction and explanations to the students, and clarifying after completing instruction facilitate the embedding of the new knowledge in the existing cognitive structure (Hativa, 2000). 


\section{A Conceptual Model for Dimensions of Effective Teaching}

The aim is to arrange all these categories and subcategories of teaching clarity, and generally of effective teaching, within a hierarchical structure of levels and sublevels. Most publications that refer to effective teaching behaviors use only two levels of dimensions: main dimensions (e.g., lesson clarity and organization) and their components (classroom strategies). The proposed model adds an intermediate-level dimension that includes clarity behaviors that mediate between the main dimension clarity and its components-classroom strategies. The breakdown of clarity into components can be repeated several times so that more than one dimension belongs to the intermediate-level category.

Thus, the new model organizes all dimensions and strategies of effective teaching in three hierarchical levels. The upper level includes the main dimension of effective teaching, e.g.; organization and clarity. The lower level contains all classroom strategies. The middle level consists of one or more layers of intermediate-level teaching dimensions that mediate between the main dimensions and the specific classroom strategies. The intermediate-level dimensions are defined either from top-downbreaking down the main dimensions into major components-or from bottom-up, by clustering (using factor or content analysis) of classroom strategies. Figure 8.1 illustrates the structure of the model:

FIGURE 8.1

Dimensions of Effective Teaching

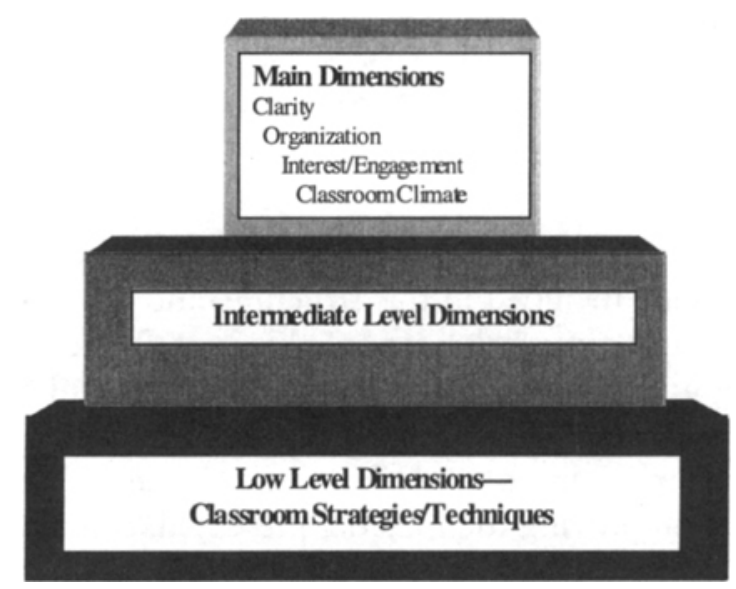


To illustrate for lesson clarity, Figure 8.2 shows the structure of the clarity dimensions in this model:

\section{FIGURE 8.2}

\section{Structure of Clarity Dimensions}

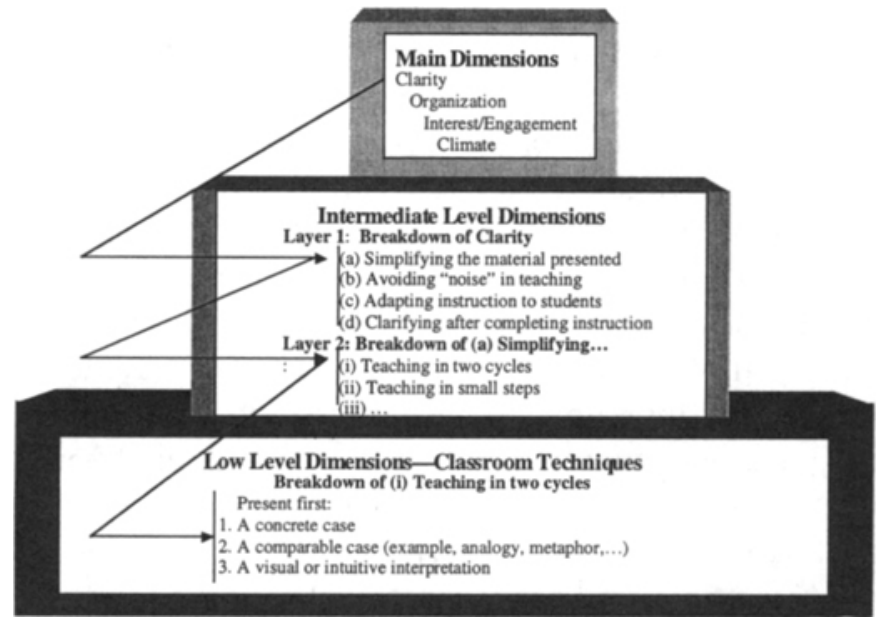

The intermediate dimension in Figure 8.2 is made up of several layers of general behaviors, and the lowest dimension consists of many classroom teaching strategies/techniques that contribute to clarity.

\section{IMPLICATIONS OF THE MODEL}

\section{Implications for Theory and Research}

The model can be modified and improved, and similar structures (of intermediate and low-level dimensions) should be identified for the other dimensions of effective teaching, such as course and lesson organization, or interest and student engagement. The studies by Hines (1982; 1985), that sorted components of clarity in accordance with their discriminating power between clear and unclear teachers, can be replicated for these other main dimensions. Identifying the strength of contribution of teaching strategies for all main dimensions of effective teaching can promote research on effective teaching in higher education. When observing teachers in their daily work or analyzing videotaped lessons, researchers can use tools that list only those strategies identified as of the strongest contribution to the main dimensions of effective teaching. 


\section{Implications for Practice}

The model suggests a framework of interconnected teaching dimensions and strategies and explains how these strategies work-how they contribute to the main dimensions of effective teaching. The model can be used to increase the general pedagogical knowledge of college and university teachers in workshops on effective teaching for faculty and in programs of educating new faculty and teaching assistants for their role as teachers. Faculty developers can present this model with the list of teacher behaviors belonging to the upper, intermediate, and lower-level dimensions of effective instruction, explain how it works, and how faculty can adapt it into their teaching. Research shows that no teacher, however effective and clear, uses more than a few dozens specific effective classroom strategies (Hativa, Barak, \& Simhi, 1998). However, faculty should be familiar with the many strategies available for effective teaching and the connections among them, as presented in the model. Knowledge of these strategies enables teachers to plan and select for classroom use those that best fit each one's perceptions, beliefs, and goals in teaching; personal style and characteristics; the particular students in class; the course; the subject area, and other contextual factors.

The model presented here can also guide the process of improving instruction at the higher education level. Understanding this model can support self-improvement efforts of teachers as well as guide the work of instructional experts/developers with faculty members to increase the teaching effectiveness. To illustrate, when instructional developers guide teachers to start an explanation of a complex concept with a visual or intuitive interpretation (see Figure 8.2), they may explain the psychological learning principles underlying this method. Then they can use the model to explain how this method (of teaching in two or more cycles, with the first one simpler than the second or third) simplifies the explanations for the students, helps them understand, and thus promotes clarity of explanations and effective learning.

A third practical application of the model is for designing student rating forms in a scientific manner. These forms usually include several items to represent each main teaching dimension, and different forms use different items to represent the same teaching dimension. The selection of items from the whole pool of possible items that represent that dimension has not been based to date on scientific methods. Knowledge of the strength of contribution of teaching strategies to each main dimension of effective teaching enables one to select only those strategies that 
most strongly contribute to that dimension. Designing the student rating forms on a scientific basis, as suggested here, will increase the validity of these ratings.

\section{REFERENCES}

Ausubel, D. P. (1978). In defense of advanced organizers: A reply to the critics. Review of Educational Research, 48, 251-258.

Benz, C. R., \& Blatt, S. J. (1994, April). Faculty effectiveness as perceived by both students and faculty: $A$ qualitative and quantitative study. Paper presented at the annual meeting of the American Educational Research Association, New Orleans, LA.

Boix, V. (1997). Of kinds of disciplines and kinds of understanding. Phi Delta Kappa, 78 (5), 381-386.

Bruner, J. S. (1960). The process of education. Cambridge, MA: Harvard University Press.

Bush, A. J., Kennedy, J. J., \& Cruickshank, D. R. (1977). An empirical investigation of teacher clarity. Joumal of Teacher Education, 28 (2), 53-58.

Cruickshank, D. R., \& Kennedy, J. J. (1986). Teacher clarity. Teaching and Teacher Education, 2(1), 43-67.

Cruickshank, D. R., Kennedy, J. J., Bush, A. J., \& Meyers, B. (1979). Clear teaching: What is it? British Journal of Teacher Education, 5 (1), 27-33.

Evans, W. E., \& Guymon, R. E. (1978, March). Clarity of explanation: A powerful indicator of teacher effectiveness. Paper presented at the annual meeting of the American Educational Research Association, Toronto, Ontario, Canada.

Feldman, K. A. (1989). The association between student ratings of specific instructional dimensions and student achievement: Refining and extending the synthesis of data from multisection validity studies. Research in Higher Education, 30(6), 583-645.

Feldman, K. A. (1997). Identifying exemplary teachers and teaching: Evidence from student ratings. In R. P. Perry \& J. C. Smart (Eds.), Effective teaching in highereducation: Research and practice (pp. 368-395). New York, NY: Agathon.

Hativa, N. (1983). What makes mathematics lessons easy to follow, understand, and remember? Two Year College Mathematics Journal, 14 (5), 398-406.

Hativa, N. (1984). Sources for learning mathematics in undergraduate university 
courses. International Journal of Mathematics Education in Science and Technology, $15(3), 375-380$.

Hativa, N. (1985). A study of the organization and clarity of mathematics lessons. International Journal of Mathematics Education in Science and Technology, 16(1), 89-99.

Hativa, N. (1995). The department-wide approach to improving faculty instruction in higher education: A qualitative evaluation. Research in Higher Education, 36 (4), 377-413.

Hativa, N. (1998). Lack of clarity in university teaching: A case study. Higher Education, 36 (3), 353-381.

Hativa, N. (2000). Teaching for effective learning in higher education. Dordrecht, Holland: Kluwer Academic Publishers.

Hativa, N., Barak, R., \& Simhi, E. (1998). Expert university teachers: Thinking, knowledge, and practice regarding effective teaching behaviors. Paper presented at the conference of the EARLI-SIG on Higher Education, Leiden, Holland.

Hativa, N., \& Raviv, A. (1996). University instructors' ratings profiles: Stability over time and disciplinary differences. Research in Higher Education, 37 (3), 341-365.

Hines, C. V. (1982). A further investigation of teacher clarity: The observation of teacher clarity and the relationship between clarity and student achievement and satisfaction. (Doctoral dissertation, The Ohio State University, Dissertation Abstracts International, 42, 3122A.)

Hines, C. V., Cruickshank, D., \& Kennedy, J. J. (1985). Teacher clarity and its relationship to student achievement and satisfaction. American Educational Research Journal, 22 (1), 87-99.

Kennedy, J. J., Cruickshank, D. R., Bush, A. J., \& Myers, B. (1978). Additional investigations into the nature of teacher clarity. Joumal of Educational Research, $72(2), 3-10$.

Marsh, H. W., \& Dunkin, M. J. (1997). Students' evaluations of university teaching: A multidimensional perspective. In R. P. Perry \& J. C. Smart (Eds.), Effective teaching in higher education: Research and practice (pp. 241-313). New York, NY: Agathon.

McKeachie, W. J. (1999). Teaching tips: Strategies, research, and theory for college and university teachers (10th ed.). Boston, MA: Houghton Mifflin.

Murray, H. G. (1983). Low-inference classroom teaching behaviors and student ratings of college teaching effectiveness. Journal of Educational Psychology, 75 (1), 138-149. 
Murray, H. G. (1985). Classroom teaching behaviors related to college teaching effectiveness (pp. 21-34). In J. G. Donald \& Sullivan (Eds.), Using teaching to improve. New Directions for Teaching and Learning, No. 23. San Francisco, CA: Jossey-Bass.

Murray, H. G. (1997). Effective teaching behaviors in the college classroom. In R. P. Perry \& J. C. Smart (Eds.), Effective teaching in higher education: Research and practice (pp. 171-203). New York, NY: Agathon.

Perkins, D. N. (1992). Understanding performances. In D. N. Perkins (Ed.), Smart schools: From training memories to educating minds (pp. 75-79). New York, NY: Free Press.

Perkins, D. N. (1998). What is understanding? In M. S. Wiske (Ed.), Teaching for understanding: A practical framework. San Francisco, CA: Jossey-Bass.

Rosenshine, B., \& Furst, N. (1971). The use of direct observation to study teaching. In R. M. W. Travers (Ed.), Second bandbook of research on teaching (pp. 122-217). Chicago, IL: Rand McNally.

Shulman, L., \& Hutchings, P. (1997). Fostering a scholarship of teaching and learning: The Camegie Teaching Academy. Menlo Park, CA: The Carnegie Foundation for the Advancement of Teaching.

Smith, S. (1978). The identification of teaching behaviors descriptive of the construct: Clarity of presentation. (Doctoral dissertation, Dissertation Abstracts International, 39(06), 3529A.)

\section{Contact:}

Nira Hativa

Chairperson, Center for Education Faculty Development

School of Education

Tel-Aviv University (TAU)

Tel Aviv 69978

Israel

97236408840

97236408157 (Fax)

Email: Nira@post.tau.ac.il

Nira Hativa holds a master's degree in mathematics from Israel and a Ph.D. in math education from Stanford University. She wears two hats: One is serving as a full-time university professor with teaching, research, and publications that focus on teaching in higher education-teaching processes; teaching effectiveness; teacher perceptions, beliefs, and thinking; and instructional development. The other hat is serving part time as faculty developer on special projects, 
working for several years with almost all faculty members in a single department or school. Her permanent position is at TAU, but she has also served in both roles at Stanford University, where she designed and produced-with the support of the Center for Teaching and Learning at Stanford-a sequence of nine videotape programs to promote effective teaching in the math/science/engineering areas. 